\title{
Predicting Post-Traumatic Growth among a Sample of Maltese Tertiary Students
}

\author{
Michael Galea \\ Mental Health Department, Faculty of Health Sciences, University of Malta, Malta \\ Email: mgalea00@yahoo.com
}

How to cite this paper: Galea, M. (2018). Predicting Post-Traumatic Growth among a Sample of Maltese Tertiary Students. Psychology, 9, 2561-2572.

https://doi.org/10.4236/psych.2018.911146

Received: September 22, 2018

Accepted: October 27, 2018

Published: October 31, 2018

Copyright (C) 2018 by author and Scientific Research Publishing Inc. This work is licensed under the Creative Commons Attribution International License (CC BY 4.0).

http://creativecommons.org/licenses/by/4.0/

\begin{abstract}
Background: Increasingly, research is indicating that individuals do report psychological growth after experiencing trauma, and not only its adverse effects. Method: In this cross-sectional correlational study among university students, we investigated their perceived stress, past traumas, subjective well-being, spirituality, positive and negative affect, and personality, together with demographic correlates. Results: Post-traumatic growth correlated with personality, spirituality, well-being and positive affect. Results from the hierarchical multiple regression analysis suggested a direct link between PTG and subjective well-being, positive affect, spirituality and personality, but no such link with negative affect. Conclusion: Personality featured prominently in predicting almost half of the variance of posttraumatic growth even after controlling for key variables. The psycho-social implications of these results were discussed.
\end{abstract}

\section{Keywords}

Posttraumatic Growth, Past Trauma, Extraversion, Conscientiousness, Wellbeing, Psycho-Spiritual Status, Perceived Stress

\section{Introduction}

People are resilient, much more than we usually think. However, despite one's own resourcefulness and experiences, the truth remains that each individual has his or her own breaking point. In effect, psychological wellbeing and holistic health lies somewhere between these two extremes, along the same continuum. In this study, we sought which variables predict posttraumatic growth among a sample of tertiary students.

A growing number of studies are indicating that people report psychological growth after experiencing trauma (Galea, 2017, 2018). Studies, mostly influenced 
by the positive psychology movement, explored this phenomenon. This was nicknamed posttraumatic growth (Tedeschi \& Calhoun, 1996), and stress-related growth (Park, Cohen, \& Murch, 1996), amongst others. Cann, Calhoun, Tedeschi, \& Lindstrom (2013) suggested that challenge to core beliefs was the main predictor of posttraumatic growth (PTG), and that a very large proportion of the sample in their study had encountered themes of PTG in their sociocultural contexts. Individuals confronted with a life-threatening illness often report posttraumatic growth or finding benefits in disease.

However, at least two controversies erupted surrounding this issue: Whether PTG reflects true positive changes, and whether what is measured is truly growth (dubbed the validity controversy). Kunst (2010) suggested that peritraumatic distress enables growth after substantial time has elapsed since victimization. Luszczynska, Durawa, Dudzinska, Kwiatkowska, Knysz, \& Knoll (2012) emphasized the defensive character of PTG, that is finding benefits in illness and changes in the function of these beliefs over time elapsing since diagnoses.

Evans (1997) found a high incidence of trauma among graduate students and low to moderate amounts of growth following trauma in a third of respondents. There does appear to be a relationship between having experienced trauma and achieving growth, specifically where the trauma experienced was of a horrific, shocking, and grotesque nature and relating to a total growth measure. What kinds of trauma are related to more specific kinds of growth was not made clear, however.

Still, a number of questions remain. Kleim and Ehlers (2009) found that PTG may be most relevant in trauma survivors who attach enduring significance to the trauma for their lives and show initial distress. Moderate levels of PTG do not seem to ameliorate post trauma psychopathology. On the other hand, Kira, Aboumediene, Ashby, Odenat, Mohanesh \& Alamia (2013) indicated that PTG was not a significant predictor of any mental health symptoms and that PTG is different from growth in non-traumatic situations. The results suggest that it is important to analyze trauma profiles rather than single trauma. Taku, Kilmer, Cann, Tedeschi, \& Calhoun (2012) suggested that the youth-reported growth does not simply reflect normative maturation. Multiple regression analysis, using participants who reported at least one traumatic event, indicated that deliberate cognitive processing appears to play an important role in PTG.

\section{Benefits of PTG}

As indicated by Haidt (2006), empirical research seems to agree on three key potential benefits of posttraumatic growth, namely: 1) feeling stronger and finding hidden abilities and inner strengths; 2) the strengthening of good relationships; and 3) the alteration of priorities and philosophies concerning the present day (appreciating more the present) and other people (prioritizing significant others in our life).

However, literature is mixed when it tries to explain the link between PTG 
and wellbeing. Park and Helgeson (2006) found a negative association or no association at all. For example, it is still debatable whether posttraumatic growth should be seen as a process or as an outcome variable. Thus, three main hypothesis have been put forward: first, that PTG leads to positive life changes which improve well-being; second, that PTG does lead to life changes but comes at the price of lowering well-being because it is a stressful journey, and finally, that PTG is a coping strategy which mediates the relationship between trauma and wellbeing (Helgeson, Reynolds, \& Tomich, 2006).

Moreover, researchers are still unclear whether posttraumatic growth is a kind of resilience, or rather resilience plays a key role in the development of PTG. Bonanno \& Mancini (2012) explained resilience as an adaptive process that occurs in the wake of trauma, to be able to maintain a healthy psychological wellbeing. On the other hand, Tedeschi \& McNally (2011) indicated an inverse relationship between PTG and resilience, where highly resilient people experienced less PTG than less resilient people.

The intriguing question is why some individuals experience more posttraumatic growth than others. Empirical research has consistently found that personality traits and mood states have significantly been linked to PTG (Stanton \& Low, 2004; Costa \& McCrae, 1992). Such variables may have a unique contribution to how a person manages to interpret life's traumas, despite the suffering and challenges inherent in them (Tedeschi \& Calhoun, 2004).

To conclude, therefore, key issues highlighted in the ever-increasing PTG empirical literature include: what is really meant by growth, what does PTG refers to, its exact relation to wellbeing, and what factors facilitate its development.

In this study, we investigated what would predict posttraumatic growth among a sample of tertiary students.

\section{Method}

\subsection{Measures}

Posttraumatic growth. Developed by Tedeschi \& Calhoun (1996), the Posttraumatic Growth Inventory (PTGI) assesses any positive outcomes in people in view of traumatic occurrences. This 21 -item inventory tries to capture five domains or factors of growth, namely: one's relating to others, new possibilities, personal strength, spiritual change, and a deeper appreciation of life. Items are rated on a 0 (I did not experience this change) to 5 (I experienced this change to a great degree) scale. Scores range from 0 to 105 . The scale has acceptable test-retest reliability (Tedeschi \& Calhoun, 1996). The short form (10 items) was used in this study. $(\mathrm{M}=32.27, \mathrm{SD}=7.70)$.

Posttraumatic Stress Disorder (PTSD) symptoms. The PTSD Checklist, Civilian Version (PCL-C) was developed by Frank Weathers and his colleagues at the United States National Center for PTSD (1993). It is a 17-item self-report measure reflecting DSM-IV symptoms of PTSD. An alpha of .94 and an overall correlation between total PCL-C and the Clinician-Administered PTSD Scale 
(CAPS) scores was found at .93 (Blanchard, Alexander, Buckley, \& Forneris, 2002). $(M=42.83, \mathrm{SD}=13.94)$.

Personality. Personality was assessed through the International Personality Item Pool (IPIP) Representations of the NEO PI R. It was developed by Goldberg (1992), and is based on the Big-Five factor structure, namely Extraversion, Agreeableness, Conscientiousness, Emotional Stability and Openness to experience. The IPIP is scored on a 5-point Likert-type scale ranging from 1 (false) to 5 (always true). The full IPIP contains 300 items. It estimates a person's standing on the 5-broad domains and 30 sub domains of personality. For the purpose of this study we utilized the short version inventory.

Stress. The Perceived Stress Scale (PSS) is a 4-item scale developed by Cohen, Kararck and Mermelstein (1983) as a global measure of perceived stress. Items are rated on a 0 (never) to 4 (very often). It was designed for use with community samples. Items include "in the last month, how often have you felt that you were unable to control the important things in your life?" and "in the last month, how often have you felt that things were going your way?" $(\mathrm{M}=8.03, \mathrm{SD}=2.54)$.

Wellbeing. This was assessed by the Satisfaction with Life Scale (SWLS), which is a short 5-item instrument designed to measure global cognitive judgments of satisfaction with one's life (Diener, Emmons, Larsen, \& Griffin, 1985). The authors believe that there is no one element to life satisfaction, but rather a recipe that includes a number of ingredients. Factors included in this short scale include: social relationships, work/school dynamics, personal satisfaction with self, spiritual life, growth and leisure. The authors indicated an alpha coefficient of .80. The alpha in this study was .82.

Spirituality. Spirituality or transcendence were measured by the Faith Maturity Scale (FMS), developed by Benson, Donahue, and Erickson (1993). It has two subgroups: faith maturity vertical (FMV) and faith maturity horizontal (FMH). The measure has good internal reliability (alpha coefficient .88). This scale measures the extent that participants seek spiritual growth. The FMS was selected for two reasons. First, its psychometric properties appear to be very acceptable. Secondly, it encompasses two main tenets of what spirituality to our knowledge must entail: love of God and neighbor. At the core of the FMS is an understanding of faith as having "vertical" (inward journey, relationship to God), and "horizontal" (outward journey, relationship to others) dimensions, with an integration of both resulting in faith maturity. The alpha reliability for the Faith Maturity Scale in this study was .90.

Positive \& Negative Affect. The Positive and Negative Affect Schedule (PANAS), was developed by Watson, Clark and Tellegen (1988). The 20-item scale comprises of two mood scales, measuring positive and negative affect. Each item is rated on a 5 -point Likert scale ( $1=$ not at all, to $5=$ extremely) to indicate the extent to which the respondent has felt this way in the indicated time frame. The authors report Cronbach's alpha coefficients ranging from .86 to .90 for the Positive Affect scale and a range of .84 to .87 for the Negative Affect scale. 
Test-retest correlations for a two-month period ranged from .47 to .68 for Positive Affect, and .39 to .71 for Negative Affect. Alpha coefficient for this study was .72 for Positive Affect $(M=31.24, \mathrm{SD}=6.93)$ and .74 for Negative Affect.

\subsection{Procedure}

After getting all ethical approval for this research, the questionnaire was sent by e-mail by the University of Malta to a random sample among all first year students who upon entry as tertiary students, indicated their willingness to partake in such studies. Response rate was $73 \%$. Inclusion criteria included tertiary students who are presently doing any undergraduate degree.

The email included a cover letter signed by the researcher, explaining the main tenets of the study, together with a link to the questionnaire. Students could participate only once in the study. A code was assigned to every completed questionnaire that was returned, and then forwarded to the researcher. The researcher had no knowledge of the identity of participants, nor of their e-mail information. The study was on a voluntary and confidential basis. Participants had one week to respond.

\subsection{Data Analysis}

In this cross-sectional and correlational study, we sought the relationship of subjective well-being to posttraumatic growth in view of past trauma experiences and perceived stress by using Pearson correlation analysis. In particular, we investigated a sample of tertiary students' perceived stress, past trauma/s, psycho-spiritual and subjective well-being status, positive and negative affect, and personality, together with demographic correlates.

We hypothesized that subjective well-being, personality and spirituality would have significant unique variance in predicting post-traumatic growth. To determine this possibility, a series of hierarchical regression analyses were run for all predictor variables with PTG entered as the criterion variable.

\section{Results}

Participants (72\% Female) were 194 tertiary students attending the University of Malta, with ages ranging from $18-32$ years $(M=21.60, S D=6.51)$. Of the participants, who were predominantly Maltese citizens (89\%), 85\% of participants were single while $15 \%$ were in a relationship or already married. Most respondents indicated as being Catholic, but only half were committed to their faith.

Table 1 shows the traumas suffered by this study's participants.

Spirituality correlated positively with subjective wellbeing $(\mathrm{r} 194, \mathrm{t}=.33, p$ $<.01)$, with positive affect $(\mathrm{r} 194, \mathrm{t}=.43, p<.001$, agreeableness $(\mathrm{r} 194, \mathrm{t}=.26, p$ $<.05)$, and also with posttraumatic growth ( $\mathrm{r} 194, \mathrm{t}=.64, p<.001)$. Research has established a consistent relationship between important life events and one's tendency toward transcendence or spirituality (Young, Cashwell \& Shcherbakova, 2000). 
Wellbeing correlated with positive affect $(\mathrm{r} 194, \mathrm{t}=.50, p<.001)$, posttraumatic growth $(\mathrm{r} 194, \mathrm{t}=.43, p<.001)$, negative affect $(\mathrm{r} 194, \mathrm{t}=-.26, p<.01)$, perceived stress $(\mathrm{r} 194, \mathrm{t}=-.43, p<.001)$, and with posttraumatic stress disorder $(\mathrm{r} 194, \mathrm{t}=-.32, p<.01)$. Extraversion correlated positively with all the personality domains and also with perceived stress ( $\mathrm{r} 194, \mathrm{t}=-.24, p<.05)$.

Table 1. Participants' recent traumas.

\begin{tabular}{ccc}
\hline $\mathbf{N}$ & \% of sample & Nature of Trauma \\
\hline 82 & $42 \%$ & Loss of a loved one \\
54 & $28 \%$ & Other not specified \\
17 & $9 \%$ & Chronic/acute illness, accident or injury \\
14 & $7 \%$ & Major changes in family responsibility \\
12 & $6 \%$ & Career or location move \\
9 & $5 \%$ & Divorce or separation \\
4 & $2 \%$ & Loss of employment \\
2 & $1 \%$ &
\end{tabular}

Besides the above correlations, posttraumatic stress disorder correlated also with negative affect $(\mathrm{r} 194, \mathrm{t}=-.36, p<.001)$, and perceived stress $(\mathrm{r} 194, \mathrm{t}=.39$, $p<.001)$. Posttraumatic growth correlated with positive affect $(\mathrm{r} 194, \mathrm{t}=.47, p$ $<.001)$, agreeableness $(\mathrm{r} 194, \mathrm{t}=.27, p<.01)$, and with conscientiousness $(\mathrm{r} 194, \mathrm{t}$ $=.27, p<.01)$.

Table 2 shows the hierarchical multiple regressions that clarify further the associations between the study variables.

Table 2. Hierarchical multiple regression predicting posttraumatic growth.

\begin{tabular}{ccccc}
\hline CriterionPredictorVariable & $\beta$ & $\underline{\mathrm{R}^{2}}$ & $\underline{\Delta \mathrm{R}^{2}}$ & $\underline{F \text { Change }}$ \\
\hline PTG & & & & \\
Step 1 & .625 & & & \\
SP & & .48 & .46 & 16.471 \\
Step 2 & .183 & & & \\
WB & .170 & & & \\
POSAF & & .49 & .46 & 12.028 \\
Step 3 & .122 & & & \\
Stress & -.078 & & & \\
PTSD & & .56 & .49 & \\
Step 4 & .216 & & & \\
Extraversion & .207 & & & \\
Conscientiousness & & & & \\
\hline
\end{tabular}

$\mathrm{N}=194 .{ }^{*} p<.05 ;{ }^{* *} p<.01 ;{ }^{* *} p<.001$. Please note that in these regressions, spirituality was entered in step 1, subjective wellbeing and positive affect in step 2, stress and PTSD in step 3, and personality (extraversion \& conscientiousness) entered in step 4 . 
It is particularly interesting for the purpose of this study to note that personality predicted almost half (49\%) of the variance of posttraumatic growth. This is more relevant considering that this unique variance was achieved after controlling for such key variables as perceived stress, past trauma, spirituality, and wellbeing variables. What does this really entail? Results point to the fact that despite the usual factors that assist in growth after trauma, one must always factor in personality input of the individuals concerned.

\section{Discussion}

Results show a direct link between PTG and spirituality, subjective well-being, positive affect, and personality. No direct link was found between PTG and negative affect.

Life's difficult dilemmas or traumas challenge our deepest held beliefs and long held assumptions. In some cases, this may ultimately lead to growth (Tedeschi \& Calhoun, 1998; Galea, 2012a, 2015). In other words, after one experiences trauma, one is open to go through a process and a journey of self-discovery, in which a new framework is constructed, after the old one based on shattered assumptions becomes defunct (Galea, 2014a). This phenomenon is sometimes labelled in research as "ego shock", with the potential to wipe out instantly our old habits, perceptions about our capabilities and assumptions, leaving only the raw experience and understanding of our existence in our environment (Campbell \& Sedikides, 1999).

Suffering may stimulate our need for meaning in life. This may be true because "people analyze and question their suffering far more than their joys" (Baumeister, 1991: p. 232). To this, Wink (1999) adds that as meaning-seekers, we find different ways of arriving at this point in life. Thus, one does well to query what relevant factors are important in human's journey of new insight and self-discovery, which ultimately results in growth (Galea, 2012b). Three factors stand out from these results that feature in one's journey toward PTG and self-discovery after trauma.

First, this study indicated that spirituality is one such factor. Research increasingly points at the relevance of this variable in this equation (Galea, 2014e). On the other hand, this study found no direct link with negative well-being. This may well imply that although spirituality may not correlate directly to decrease of pain and suffering, it may have a unique impact in providing a framework and important perspective through which trauma may be more easily borne (Galea, 2008). In other words, spirituality results in helping to increase inner joy despite life's difficulties.

Researchers such as Gorsuch (1994b), Galea (2007, 2009, 2010), Mahoney \& Graci (1999), and Westgate (1996), viewed spirituality as an important construct for well-being, especially against negative life events. Miller and Thoreson (1999) found that whenever spirituality was involved, it was always found significantly related to healthy outcomes, and inversely related to disorders. As indicated in 
this study, transcendence may be beneficial especially to trauma victims, as it may ease the negative impact of their trauma, by increasing affective well-being.

Secondly, cognitive well-being and positive affect both predicted posttraumatic growth, as expected. Thus, thinking directly affects one's feelings in that having good perception about ourselves helps us feel and do better.

Finally, personality was found to be the highest contributor to growth among this sample. Two key personality variables, namely extraversion and conscientiousness, were found to feature prominently in the equation of what mostly predicts PTG. Personality is increasingly found to be quite relevant in the positive psychology movement in general, and in particular in this equation for one to move forward in his or her own self-discovery journey of growth. Results from this study highlighted the key relevance of two such components: conscientiousness and extraversion, for one's successful journey of growth after trauma.

Conscientiousness has to do with how we control, regulate and direct our impulses. Conscientious persons normally avoid trouble and achieve high levels of success through purposeful planning. They are persistent in their pursuits and reliable in their endeavors. They are self-efficacious, good achievers, cautious and generally, very self-disciplined. Being reliable, organized and sensitive do factor in, in increasing one's status of positive affect.

Together with Conscientiousness, individuals who also score high on PTG had also high standing on Extraversion. Extraversion is marked by pronounced engagement with one's environment around. They are energetic and prone to experience positive emotions. Overall, they are assertive, friendly and prefer to keep busy. These features seem to be quite helpful in facing daily challenges with a proactive approach, taking initiative and trying to find alternatives to whatever perils one may be going through, rather than taking a victim's approach.

Moreover, extroverts find social situations more rewarding than introverts, not because they are more sociable but because they are more sensitive to the rewards inherent in most situations (Lucas \& Diener, 2008). This in turn will explain their high standing on posttraumatic growth. Energetic individuals who may be assertive and pro-social seem to be better equipped to counter daily life's stresses. To this effect, Galea (2014b) found that extraversion had unique variance in predicting burnout and other life's stressors.

It is important to reiterate the increasing attention that extraversion is steadily gaining within related studies. Research has indicated three main reasons why we should study extraversion, namely a) its importance to personality (Costa \& McCrae, 1992a), b) it predicts well-being across a broad domain including cognitive and social well-being (Eaton \& Funder, 2003), and c) extraversion predicts risks and resilience for other forms of psychotherapy (Widiger and Samuel, 2005).

\section{Limitations and Future Directions}

Because this study is basically correlational in nature, no inferences of causality 
can be made. Second, the study's reliance upon self-reported and recalled data may have introduced sources of error. Individuals' responses may have become distorted over time.

Despite these limitations, this study's strengths are noteworthy. The exploratory nature of the impact of posttraumatic growth on this Maltese sample of tertiary students is an important strength. Posttraumatic growth is a novel area among this culture, which adds to the increasing empirical research attesting to its value in view of past trauma. Another feature of this study was its multidimensional focus in bundling together measures of personality and psycho-spiritual well-being, singly identified as important in similar research (Costa \& McCrae, 1992). Their simultaneous application here allowed for a more sophisticated analysis of posttraumatic growth on trauma survivors.

\section{Conclusion}

Finally, this study showed the need to factor in personality variables, such as extraversion and conscientiousness, into the equation of PTG studies. Individuals in this study who faced growth after trauma tended to have a personality profile that was high on both extraversion and conscientiousness. The need to sift through the complex reality that surrounds this phenomenon of growth after a history of trauma is required to produce a better understanding of the exact dynamics inherent to it.

\section{Conflicts of Interest}

The author declares no conflict of interest.

\section{References}

Baumeister, R. F. (1991). Meanings of Life. New York: Guilford.

Benson, P. L., Donahue, M. J., \& Erickson, J. A. (1993). The Faith Maturity Scale: Conceptualization, Measurement and Empirical Validation. Research in the Social Scientific Study of Religion, 5, 1-26.

Blanchard, E. B., Hickling, E. J., Galovsky, T., \& Veazey, C. (2002). Emergency Room Vital Signs and PTSD in a Treatment Seeking Sample of Motor Vehicle Accident Survivors. Journal of Traumatic Stress, 15, 199-205. https://doi.org/10.1023/A:1015299126858

Bonanno, G. A., \& Mancini, A. D. (2012). Beyond Resilience and PTSD: Mapping the Heterogeneity of Responses to Potential Trauma. Psychological Trauma: Theory, Research, Practice, and Policy, 4, 74-83. https://doi.org/10.1037/a0017829

Campbell, W. K., \& Sedikides, C. (1999). Self-Threat Magnifies the Self-Serving Bias: A Meta-Analytic Integration. Review of General Psychology, 3, 23-43. https://doi.org/10.1037/1089-2680.3.1.23

Cann, A., Calhoun, L. G., Tedeschi, R. G., \& Lindstrom, C. M. (2013). The Relationship of Core Belief Challenge, Rumination, Disclosure, and Sociocultural Elements to Posttraumatic Growth. Psychological Trauma: Theory, Research, Practice, and Policy, 5, 50-55. https://doi.org/10.1037/a0022030

Cohen, S., Kamarck, T., \& Mermelstein, R. (1983). A Global Measure of Perceived Stress. 
Journal of Health and Social Behavior, 24, 385-396. https://doi.org/10.2307/2136404

Costa, P. T., \& McCrae, R. R. (1992). Normal Personality Assessment in Clinical Practice: The NEO Personality Inventory. Psychological Assessment, 4, 5-13. https://doi.org/10.1037/1040-3590.4.1.5

Costa, P. T., \& McCrae, R. R. (1992a). Four Ways Five Factors Are Basic. Personality and Individual Differences, 13, 653-665. https://doi.org/10.1016/0191-8869(92)90236-I

Diener, E., Emmons, R. A., Larsen, R. J., \& Griffin, S. (1985). The Satisfaction with Life Scale. Journal of Personality Assessment, 49, 71-75. https://doi.org/10.1207/s15327752jpa4901_13

Eaton, L. G., \& Funder, D. C. (2003). The Creation and Consequences of the Social World: An Interactional Analysis of Extraversion. European Journal of Personality, 17, 375-395. https://doi.org/10.1002/per.477

Evans, J. H. (1997). Trauma and Posttraumatic Growth among Graduate Level Counselor Education Students: What Is Their Relative Incidence and What Relationships Do they share? Dissertation Abstracts International Section A: Humanities \& Social Sciences, $58,1600$.

Galea, M. (2009). Extraversion, Childhood Trauma and Family Environment as Predictors of Happiness and Well-Being among Maltese University Students. Advances in Psychology Research, 65, 15-19.

Galea, M. (2010). Does Child Maltreatment Mediate Family Environment and Psychological Well-Being? Psychology, 1, 143-150. https://doi.org/10.4236/psych.2010.12019

Galea, M. (2012a). Studying the Incremental Validity of Family Environment among Maltese University Students with Past Mental Trauma. Pastoral Psychology, 61, 211-220. https://doi.org/10.1007/s11089-011-0389-9

Galea, M. (2012b). A Conspiracy of Silence? Addressing Childhood Trauma in Malta: An Empirical Review. In R. A. Turner, \& H. O. Rogers (Eds.), Child Abuse: Indicators, Psychological Impact and Prevention (5th ed., pp. 85-98). Hauppauge, NY: NOVA Publishers.

Galea, M. (2014a). The Progressive Impact of Burnout on Maltese Nurses. SOP Transactions on Psychology, 2, 1-8. https://doi.org/10.15764/STP.2014.01001

Galea, M. (2014b). Assessing the Incremental Validity of Spirituality in Predicting Nurses Burnout. Archive for Psychology of Religion, 36, 118-136.

https://doi.org/10.1163/15736121-12341276

Galea, M. (2014e). The Relationship of Personality, Spirituality and Posttraumatic Growth to Subjective Wellbeing. Open Access Library Journal, 1, e1069. https://doi.org/10.4236/oalib.1101069

Galea, M. (2015). Burnout and Vocational Satisfaction: An Incremental Validity Study. In T. N. Winston (Ed.), Handbook on Burnout and Sleep Deprivation (13th ed., pp. 201-217). Hauppauge, NY: NOVA Publishers.

Galea, M. (2017). Vicarious PTG after Fireworks Trauma. Psychology, 8, 2496-2515.

Galea, M. (2018). The Two Faces of Spirituality in Time of Traumatic Loss: A Thematic Analysis Study. Open Journal of Social Sciences, 6, 49-63.

Galea, M., Ciarrocchi, J. W., Piedmont, R. L., \& Wicks, R. J. (2008). The Impact of Child Abuse on the Psycho-Spiritual and Religious Status of Maltese College Students. Pastoral Psychology, 57, 147-159. https://doi.org/10.1007/s11089-008-0159-5

Galea, M., Ciarrocchi, J. W., Piedmont, R. L., \& Wicks, R. J. (2007). Child Abuse, Personality, and Spirituality as Predictors of Happiness in Maltese College Students. Re- 
search in the Social Scientific Study of Religion, 18, 141-154. https://doi.org/10.1163/ej.9789004158511.i-301.57

Goldberg, L. R. (1992). The Development of Markers for the Big-Five Factor Structure. Psychological Assessment, 4, 26-42. https://doi.org/10.1037/1040-3590.4.1.26

Gorsuch, R. L. (1994b). Religious Aspects of Substance Abuse and Recovery. Journal of Social Issues, 51, 65-83. https://doi.org/10.1111/j.1540-4560.1995.tb01324.x

Haidt, J. (2006). The Happiness Hypothesis: Putting Ancient Wisdom and Philosophy to the Test of Modern Science. London: Arrow Books.

Helgeson, V. S., Reynolds, K. A., \& Tomich, P. L. (2006). A Meta-Analysis Review of Benefit Finding and Growth. Journal of Consulting and Clinical Psychology, 74, 797-816. https://doi.org/10.1037/0022-006X.74.5.797

Kira, I. A., Aboumedience, S., Ashby, J. S., Odenat, L., Mohanesh, H., \& Alamia, H. (2013). the Dynamics of Post-Traumatic Growth across Different Trauma Types in a Palestinian Sample. Journal of Loss \& Trauma, 18, 120-139. https://doi.org/10.1080/15325024.2012.679129

Kleim, B., \& Ehlers, A. (2009). Evidence for a Curvilnear Relationship between Posttraumatic Growth and Posttrauma Depression and PTSD in Assault Survivors. Journal of Traumatic Stress, 22, 45-52. https://doi.org/10.1002/jts.20378

Kunst, M. J. J. (2010). Peritraumatic Distress, Posttraumatic Stress Disorder Symptoms, and Posttraumatic Growth in Victims of Violence. Journal of Traumatic Stress, 23, 514-518. https://doi.org/10.1002/jts.20556

Lucas, \& Diener (2008). What Can We Learn about National Differences in Happiness from Individual Responses? A Multilevel Approach. In F. J. R. van de Vijver, D. A. van Hemert, \& Y. H. Poortinga (Eds.), Psychological Data at Individual and Country Level: Issues of Aggregation and Disaggregation (pp. 223-248). New York, NY: Lawrence Erlbaum Associates.

Luszczynska, A., Durawa, A. B., Dudzinska, M., Kwiatkowska, M., Knysz, B., \& Knoll, N. (2012). The Effects of Mortality Reminders on Posttraumatic Growth and Finding Benefits among Patients with Life-Threatening Illness and Their Caregivers. Psychology \& Health, 27, 1227-1243.

Mahoney, M. J., \& Graci, G. M. (1999). The Meanings and Correlates of Spirituality: Suggestions from an Exploratory Survey of Experts. Death Studies, 23, 521-528.

Miller William, R., \& Thoresen Carl, E. (1999). Spirituality and Health. In R. Miller William (Ed.), Integrating Spirituality into Treatment. Washington DC: American Psychological Association.

Park, C. L., \& Helgeson, V. S. (2006). Introduction to the Special Section: Growth Following Highly Stressful Life Events-Current Status and Future Directions. Journal of Consulting and Clinical Psychology, 74, 791-796.

Park, C. L., Cohen, L. H., \& Murch, R. L. (1996). Assessment and Prediction of Stress-Related Growth. Journal of Personality, 64, 71-105. https://doi.org/10.1111/j.1467-6494.1996.tb00815.x

Stanton, A. L., \& Low, C. (2004). Toward Understanding Posttraumatic Growth: Commentary on Tedeschi and Calhoun. Psychological Inquiry, 15, 76-80.

Taku, K., Kilmer, R. P., Cann, A., Tedeschi, R. G., \& Calhoun, L. G. (2012). Exploring Posttraumatic Growth in Japanese Youth. Psychological Trauma: Theory, Research, Practice, and Policy, 4, 411-419.

Tedeschi, R. G., \& Calhoun, C. G. (1996). The Posttraumatic Growth Inventory: Measuring the Positive Legacy of Trauma. Journal of Traumatic Stress, 9, 455-471. 
https://doi.org/10.1002/jts.2490090305

Tedeschi, R. G., \& Calhoun, C. G. (2004). The Foundations of Posttraumatic Growth: New Considerations. Psychological Inquiry, 15, 1-18. https://doi.org/10.1207/s15327965pli1501_01

Tedeschi, R. G., \& Calhoun, L. (1998). Posttraumatic Growth: Future Directions. In R. G. Tedeschi, C. L. Park, \& L. G. Calhoun (Eds.), Post-Traumatic Growth: Positive Changes in the Aftermath of Crisis (p. 24). New York, NY: Routledge.

Tedeschi, R. G., \& McNally, R. J. (2011). Can We Facilitate Posttraumatic Growth in Combat Veterans? American Psychologist, 66, 19-24.

Watson, D., Clark, L. A., \& Tellegen, A. (1988). Development and Validation of Brief Measures of Positive and Negative Affect: The PANAS Scales. Journal of Personality and Social Psychology, 54, 1063-1070. https://doi.org/10.1037/0022-3514.54.6.1063

Westgate, C. E. (1996). Spiritual Wellness and Depression. Journal of Counseling \& Development, 75, 26-35. https://doi.org/10.1002/j.1556-6676.1996.tb02311.x

Widiger, T. A., \& Samuel, D. B. (2005). Diagnostic Categories or Dimensions? A Question for the Diagnostic and Statistical Manual of Mental Disorders (5th ed.). Journal of Abnormal Psychology, 114, 494-504.

Wink, P. (1999). Addressing End-of-Life Issues: Spirituality and Inner Life. Generations Spring, 23, 75-81.

Young, J. S., Cashwell, C. S., \& Shcherbakova, J. (2000). The Moderating Relationship of Spirituality on Negative Life Events and Psychological Adjustment. Counseling \& Values, 45, 49-58. https://doi.org/10.1002/j.2161-007X.2000.tb00182.x 